\title{
A study on cervical cytopathology in HIV positive pregnant women in Southern part of Assam, India
}

\author{
Arun Paul Choudhury, Tanaya Acharyya*
}

Department of Obstetrics and Gynecology, Silchar Medical College and Hospital, Silchar, Assam, India

Received: 26 June 2021

Revised: 31 July 2021

Accepted: 03 August 2021

\section{*Correspondence:}

Dr. Tanaya Acharyya,

E-mail: Tanayaacharyya.tiarra@gmail.com

Copyright: ( ) the author(s), publisher and licensee Medip Academy. This is an open-access article distributed under the terms of the Creative Commons Attribution Non-Commercial License, which permits unrestricted non-commercial use, distribution, and reproduction in any medium, provided the original work is properly cited.

\section{ABSTRACT}

Background: The association between abnormal cervical cytology and HIV infection status in pregnant women was evaluated to correlate with CD4 cell count, viral load and ART compliance in HIV positive pregnant patients with the presence of ASC-US, LSIL and HSIL.

Methods: Cervical samples were collected at the Antenatal Clinic of Silchar Medical College and Hospital. An Ayre's spatula was used to collect samples from the ectocervix and a cytology brush to collect samples from the endocervix.

Results: Of a total of 75 antenatal attendees, 43 were HIV positive and 32 were HIV negative. Abnormal cytology $(\mathrm{N}=26,60.46 \%)$ was more common in HIV positive group compared to the HIV negative group $(\mathrm{N}=7,21.87 \%)$ with a $\mathrm{p}$ value of $<0.05$. Cytological abnormalities were found to be associated with immunosuppression, defined as CD4 count $<200$ cells $/ \mathrm{mm}^{3}$ and was also associated with high viral $\operatorname{load}\left(>10,000 / \mathrm{mm}^{3}\right)$ and poor treatment follow up with ART.

Conclusions: HIV positive pregnant women are more likely to have cervical lesions as compared to the HIV negative. This higher frequency of abnormal findings in PAP cytology in HIV positive pregnant women with higher viral loads suggest association between preinvasive cervical lesions and human immune deficiency.

Keywords: Cervical dysplasia, HIV infection, Pregnant woman, Assam

\section{INTRODUCTION}

Assam is categorised as a low HIV prevalence state with an estimated adult HIV prevalence of $0.07 \%$, which is lower than national prevalence of $0.27 \%$. According to the Assam state AIDS control society data 2015, the geographical distribution of HIV epidemic in Assam shows specific focus of the epidemic in Barak Valley region of South Assam with prevalence $>1 \%$.

ANC attendees are considered as proxy for general population, which showed a rising trend in HIV prevalence in southern province. ${ }^{1}$ A study by Bhattacharjya et al also showed that the two southern districts- Cachar et al have the highest percentage of cases around $25 \%$ in comparison with other districts. ${ }^{2}$ In India, the prevalence of HIV infection in pregnant women ranges from $0.7 \%$ to $1.2 \% .^{3}$
Cervical intraepithelial neoplasia occurs as a continuum of atypical metaplasia caused as a result of persistent HPV infection due to immune suppression. The role of frequent HPV infection in HIV infected woman is clearly established. HIV mediated immune suppression predisposes to increased HPV mediated cervical cytological abnormalities. In this study, we have evaluated the association between abnormal cervical cytology findings and HIV infection status in pregnant women and to relate the CD4 cell count and viral load of these HIV positive pregnant women with the presence of ASC-US, LSIL and HSIL.

\section{METHODS}

The present study was conducted in Silchar Medical College and Hospital, Assam, a tertiary care centre. The 
study was in accordance with the recommendations of the Declaration of Helsinki and was approved by the ethical committee members. ${ }^{4}$ All the patients included in the study signed an informed consent form. A total of 75 pregnant women were recruited to the study between February 2020 and April 2021, 43 of whom were confirmed HIV positive and 32 were HIV negative. The clinical and demographic data of these patients were collected using a specific questionnaire applied during antenatal examination. The study inclusion criteria consisted of all pregnant women attending the antenatal clinic between 21 and 28 weeks of pregnancy with similar age, parity and marital status. The patients were given information about the HIV infection and the objectives, constraints and the benefit of the study. Eligible pregnant women who gave consent to participate in the study were offered HIV antibody screening using two enzyme linked immunosorbent assays (ELISA). Discordant samples by ELISA were confirmed by a western blot technique. Two weeks after the HIV screening test, all HIV positive women were enrolled with an almost equivalent number of frequency matched HIV negative women similar in age and parity. The laboratory workers and the nurses were blinded to the HIV serostatus. A Pap smear, CD4 absolute lymphocyte count and HIV viral load detection by PCR was done. Cervical samples were obtained from the ectocervix by using Ayre's spatula and from the endocervix using cyto-brush. Samples were distributed evenly on glass slides, duly identified and fixed using a mixture of polyethylene glycol and $70 \%$ ethanol to prevent drying. The smears were then submitted to PAP staining.Data collected in the study were stored and analysed using SPSS software version 24. Statistical significance was defined as $\mathrm{p}<0.05$.

\section{RESULTS}

Of the 75 pregnant women studied, 43 were HIV positive and 32 HIV negative. With respect to cytology, 26 $(60.46 \%)$ of the HIV positive women and $7(21.87 \%)$ of the HIV negative women tested positive for abnormal cytology. A greater frequency of intraepithelial lesions were found in HIV positive compared to HIV negative women, $\mathrm{p}$ value $<0.001$ (Table 1 ). 17 cases of ASC-US were found, 12 in the HIV positive and 5 in the HIV negative (70.6\% vs $29.4 \%$ respectively), p value 0.0179 $(<0.05)$, statistically significant. 13 cases of LSIL were found, 11 in the HIV positive and 2 in the HIV negative $(84.6 \%$ vs $15.4 \%$ respectively) with $p$ value $0.0005(<0.05)$, statistically significant. Only 3 cases of HSIL were found in all the smears analysed, all those patients were HIV positive (100\%), with $\mathrm{p}$ value 0.0253 $(<0.05)$, that is statistically significant. Thus, abnormal cytology was related to HIV status, more found in HIV positive than in HIV negative. When the presence of cytological abnormalities were correlated with CD4 cell count in the HIV positive patients, these abnormalities were found to be more common in women who were immune-deficient, CD4 cell count $<200 / \mathrm{mm}^{3}$ with p value $0.0249(<0.05)$. Thus, abnormal cervical cytology was related to immunosupression, more in immunodeficiency than in immunosufficiency. With respect to the viral load, the highest frequency of abnormal cytology was found in patient with a viral load $>10,000$ copies $/ m$. This association was not however statistically significant, $p$ value $0.0912(>0.05)$. On evaluation of the patients in relation to their intake of ART, patients who had been well compliant to ART therapy had lesser percentage of abnormal cytology, and the correlation was statistically significant, p value $0.0238(<0.05)$.

\section{DISCUSSION}

The highest frequency of abnormal cervical cytology was found in the group of HIV positive pregnant women and was statistically significant. Similar results were found in the studies conducted by Auge et al and Moodley et al where significant difference with respect to human immunodeficiency virus was established when smears with only the cytopathic effects of HPV were considered. ${ }^{5,6}$

In the present study, the presence of lesions was associated with immunosuppression. Bearing with the fact that majority of the patients with cervical dysplasia in the HIV positive group had CD4 cell counts $<200 / \mathrm{mm}^{3}$. This finding was in accordance with the findings of Adam et al who reported that cytological abnormalities were 8 times more frequent in HIV positive patients, were also twice as common in women with a CD4 cell count $<200 / \mathrm{mm}^{3} .{ }^{7}$ In contrast, Coelho et al evaluated $115 \mathrm{HIV}$ positive women and reported higher CD4 counts associated with LSIL and HSIL, however these results were not statistically significant. ${ }^{8}$ Nevertheless, Zimmermman et al reported no difference in CD4+ T cell count in the presence or absence of LSIL or HSIL. ${ }^{9}$ The finding of higher viral counts (>10,000 copies $/ \mathrm{mm}^{3}$ ) when lesions were present, was conforming with the results reported by Masad et al and emphasises the close association between HIV/HPV and a consequent cytological abnormality. ${ }^{10}$ According to the present study, HIV patients on ART had lesser percentage of cervical abnormalities as compared to those without ART, the difference being statistically significant. Firnhaber et al stated that, as HPV infection is an immunomodulated disease, there is some hope that HIV ART would improve regression rates and prevent the progression of cervical dysplasia. ${ }^{11}$

Table 1: Association between HIV status and cytology findings.

\begin{tabular}{|llllll|}
\hline HIV status & Abnormal smear N $(\%)$ & ASC-US N $(\%)$ & ASC-H N $(\%)$ & LSIL N (\%) & HSIL N (\%) \\
\hline Positive & $26(78.787)$ & $12(70.6)$ & $0(0)$ & $11(84.6)$ & $3(100)$ \\
\hline Negative & $7(21.21)$ & $5(29.4)$ & $0(0)$ & $2(15.4)$ & $0(0)$ \\
\hline Total & $33(100)$ & $17(100)$ & $0(0)$ & $13(100)$ & $3(100)$ \\
\hline
\end{tabular}


Table 2: Frequency of abnormal smear correlated with immunological status in HIV positive woman.

\begin{tabular}{|c|c|c|c|c|c|c|c|}
\hline \multirow{3}{*}{$\begin{array}{l}\text { Abnormal } \\
\text { cytology }\end{array}$} & \multirow{2}{*}{\multicolumn{2}{|c|}{$\begin{array}{l}\text { Immunodeficiency } \\
\text { CD4 cell count }(<200 \\
\left.\text { cells } / \mathbf{m m}^{3}\right)\end{array}$}} & \multirow{2}{*}{\multicolumn{2}{|c|}{$\begin{array}{l}\text { Immuno sufficiency } \\
\text { CD4 cell count }(>200 \\
\left.\text { cells } / \mathbf{m m}^{3}\right)\end{array}$}} & \multirow{2}{*}{\multicolumn{2}{|c|}{ Total }} & \multirow[b]{2}{*}{$P$ value } \\
\hline & & & & & & & \\
\hline & $\mathbf{N}$ & $\%$ & $\mathbf{N}$ & $\%$ & $\mathbf{N}$ & $\%$ & \multirow{5}{*}{0.0249} \\
\hline ASC-US & 10 & 83.33 & 2 & 16.67 & 12 & 100.00 & \\
\hline LSIL & 4 & 36.36 & 7 & 63.64 & 11 & 100.00 & \\
\hline HSIL & 3 & 100.00 & 0 & 0.00 & 3 & 100.00 & \\
\hline Total & 19 & 73.08 & 7 & 26.92 & 26 & 100.00 & \\
\hline
\end{tabular}

Table 3: Frequency of abnormal cytology correlated with viral load in HIV positive pregnant women.

\begin{tabular}{|llllllllll|}
$\begin{array}{l}\text { Pre-invasive } \\
\text { lesion of } \\
\text { cervix }\end{array}$ & $\begin{array}{l}\text { Below detection } \\
\text { limit }\end{array}$ & $\mathbf{N}$ & $\mathbf{\%}$ & $\mathbf{N}$ & $\mathbf{\%}$ & $\mathbf{N}$ & $\mathbf{\%}$ & $\mathbf{N}$ & $\mathbf{\%}$ \\
\hline ASC-US & 5 & 41.67 & 1 & 8.33 & 6 & 50.00 & 12 & 100.00 \\
\hline LSIL & 0 & 0.00 & 2 & 18.18 & 9 & 81.82 & 11 & 100.00 \\
\hline HSIL & 0 & 0.00 & 0 & 0.00 & 3 & 100.00 & 3 & 100.00 \\
\hline Total & 5 & 19.23 & 3 & 11.54 & 18 & 69.23 & 26 & 100.00 \\
\hline
\end{tabular}

Table 4: Frequency of abnormal cytology in HIV positive pregnant women depending on ART intake.

\begin{tabular}{|llll|}
\hline Abnormal cytology & HIV positive & & Total \\
& On anti-retroviral therapy & Without anti-retroviral therapy & $12(100)$ \\
\hline ASC-US & $1(8.3)$ & $11(91.7)$ & $11(100)$ \\
\hline LSIL & $6(54.5)$ & $5(45.5)$ & $3(100)$ \\
\hline HSIL & $0(0)$ & $3(100)$ & 0.0238 \\
\hline
\end{tabular}

\section{Limitations}

Although the inclusion of HIV negative pregnant women allowed us to confirm that cervical dysplasias were HIV related, this study could not establish a causal association between HIV infection and cervical abnormalities. The other factors such as age, age at first intercourse, parity, STDs and number of sexual partners may be confounding factors in the analysis of this association. We were not able to collect information about the HPV infection, limiting our ability to study their association with cervical abnormalities in HIV infected pregnant women.

\section{CONCLUSION}

According to the ICMR data, Cachar district in south Assam has the highest prevalence of Ca cervix (15.4\%), as compared to the other region in Assam. With an increased association of cervical dysplasia or squamous intraepithelial lesions observed among HIV infected pregnant women in the southern part of Assam and considering the fact that cervical dysplasia may evolve into invasive cervical cancer with inadequate follow up, this could become an increasing problem in these populations. However, with adequate screening cytology (Pap smear), ART intake and conventional follow up guidelines, it would be possible to curb the incidence of cervical cytological abnormalities in HIV positive pregnant women to a considerable extent.

\section{ACKNOWLEDGMENTS}

I wish to extend my special thanks to Dr. Ananya Debnath, post graduate trainee, Department of Pathology, SMCH for her contribution in cytology.

\section{Funding: No funding sources}

Conflict of interest: None declared

Ethical approval: The study was approved by the Institutional Ethics Committee

\section{REFERENCES}

1. Assam State AIDS Control Society, Government of Assam. HIV scenario in Assam, 2015. Available at: https://asacs.assam.gov.in/portlets/hivscenerioinassa m\#: :text=Assam\%20is\%20categorized $\% 20$ as $\% 20$ a, the $\% 20$ National $\% 20$ Prevalence $\% 20$ of $\% 200.26 \% 25$. \&text=T. Accessed on 17 June 2021.

2. Bhattacharjya C, Pathak G, Goswami T, Singh YM, Deka R, Sen M, et al. Emerging HIV Epidemic in the North-Eastern State of Assam, India: An Exploratory Study Using Mixed-Methods Approach. World J AIDS. 2018;8:21-36.

3. Shah I, Lala M, Damania K. Prevalence of HIV infection in pregnant women in Mumbai, India: Experience from 1993-2004 and 2008. J Family Med Prim Care. 2017;6(2):240-2.

4. World Medical Assembly, Helsinki, Finland. Declaration of Helsinki- Recommendations guiding 
medical doctors in biomedical research involving human subjects, 1964. Available at: rcodelsur.net/plp/declaration-of-helsinki1964citation. Accessed on 17 June 2021.

5. Auge APF. Frequency of cervical intraepithelial neoplasia in carriers of the human immunodeficiency virus. Revista Brasileira Ginecol Obstet. 2000;22(9):573-7.

6. Moodley M, Garib R. The significance of human papillomavirus infection detected by cervical cytology among women infected with the human immunodeficiency virus. J Obstet Gynaecol. 2004;24(8):903-6.

7. Adam Y, Gelderen CJ, Bruyn G, McIntyre JA, Turton DA, Martinson NA. Predictors of persistent cytologic abnormalities after treatment of cervical intraepithelial neoplasia in Soweto, South Africa: a cohort study in a HIV high prevalence population. BMC Cancer. 2008;8:211.
8. Coelho RA. Relationship between cytopathological diagnosis of cervical intraepithelial neoplasia and CD4 cell and viral load indices in HIV-seropositive patients. Revista Brasileria Ginecol Obstet. 2004;26(2):97-102.

9. Zimmermmann JB. Association between CD4 T lymphocyte count and the severity of cervical intraepithelial neoplasia diagnosed by histopathology in HIV-infected women. Brazilian J Gynecol Obstet. 2006;28(6):345-51.

10. Masad S. Prevalence and predictors of squamous cell abnormalities in Papanicolaou smears from women infected with HIV-1. J Acquired Immune Deficiency Syndromes. 1999;21(1):33-41.

11. Firnhaber C, Michew P. Cervical cancer and the human immunodeficiency virus: a review. Southern African J HIV Med. 2009;10(3):23-7.

Cite this article as: Choudhury AP, Acharyya T. A study on cervical cytopathology in HIV positive pregnant women in Southern part of Assam, India. Int J Reprod Contracept Obstet Gynecol 2021;10:3490-3. 